\title{
Nepal: Public Health in 2015
}

\author{
Sarmila Dhakal ${ }^{1}$, Anupa Rijal ${ }^{2}$ \\ ${ }^{1}$ Bachelor in Public Health, Maharajgunj Medical Campus, Tribhuvan University ${ }^{2} \mathrm{MPH}$ candidate, University of Southern Denmark
}

\section{Received:}

3 February 2016

Revised:

28 March 2016

\section{Accepted:}

August 12016

\section{${ }^{\star}$ Correspondence:}

dhakalsharu@gmail.com

Kathmandu School of

Medical Technology,

Kathmandu, Nepal
The year 2015 was filled with tremulous events in political, economic, social and environmental sectors of Nepal. It was a historical year to witness the end of civil war formally by promulgation of Nepal's new constitution. However, moving towards the implementation, challenges remain. Earthquakes in April and May, followed by economic blockade which started in September 2015 had severe impact on Nepal's infrastructures. It also further aggravated the prevailing humanitarian crisis after the earthquakes leaving thousands dead and jeopardizing livelihoods of many. The growth in economy (Gross Domestic Product) is projected to decline from $6 \%$ to $2 \%$, further escalating inflation and overall wellbeing of the nation. Amidst the public health emergencies created by political agitation and natural calamities, Nepal has shown a great deal of resilience to tackle these challenges. So with the beginning of the New Year 2016, Nepal looks forward in rebuilding, supporting and uplifting health and wellbeing of all the citizens across the nation. Here, we reflect public health in Nepal in 2015.

\section{Natural and man-made disasters}

The earthquake of magnitude 7.8 Rs hit Nepal on 25th April and 12th May caused the massive destructions of physical infrastructures, deaths of around 8,800 people and affecting 8 million lives across the country. Along with this, physical injuries leading to disabilities and post-traumatic stress disorder was in rise. Women and children were even more affected by the disaster. There were altogether 60,000 pregnant women and 637,000 adolescent girls in most severely affected fourteen districts. An estimated 10,000 babies born every month across these districts and about 1,500 pregnant women are likely to experience complications during pregnancy and childbirth requiring medical care(1). Government declared the fourteen districts as emergency and mobilized the search and rescue operations and also called for the international assistance. International assistance in terms of search and rescue team, relief supplies, medical teams and donations poured in. Government managed the temporary shelter and distributed the financial and material to the victim's family. More than 87 medical teams were mobilized. The injured were treated in nearby health facilities or camps.

Around 461 Public Health facilities have been completelydestroyed which includes 5 Hospitals, 12 Primary Health Care Centers, 417 Health Posts, and 16 Private Hospitals which have directly affected the health service delivery in the emergency situations. The long term plan of the government in aftermath of the earthquakes includes the strategy to build the disable friendly concrete building for HPs, PHCs and hospitals. It also focuses on the establishment of emergency unit in zonal level, facilities for trauma care and geriatric services (2).

Similarly, the economic blockade on Nepal by India has pushed Nepal Health system to function under scarcity of essential medicines, vaccines and other necessary supplies in hospitals. This has not just periled Nepal's hope for sustainable and rapid recovery after April earthquakes, but also has faltered century's long relation between neighbors. The threat of current blockade on population health cannot be neglected, as elsewhere in the world economic sanctions, has created humanitarian crisis. UNICEF and number of international organizations have already warned for a soaring humanitarian crisis in the face of blockade and violent protests in Nepal's southern plains by ethnic Madhesis and Tharus.

\section{Constitutional guarantee in health}

Nepal's newly promulgated constitution in Sept. 20, 2015, guarantees health as a fundamental human right. Right to health has mentioned four components including right to basic health services free of cost, right to be informed about the treatment of his/her illness, right to equal access to health services and right to access clean drinking water and sanitation. While, this is an important milestone towards universal health coverage, sustained efforts from the government, Nepal's international partners and civil society are necessary to build up the institutional and financial capacity of health system to provide constitutionally guaranteed free basic health services for all where they needed, and when they needed.

\section{Slightly off from MDGs on child health}

Nepal was slightly behind targets for MDGs goals on child health from achieving. According to the latest MDG assessment report 2013, the estimated Under 5 Morality Rate (U5MR) and Infant Mortality Rate (IMR) was 54 and 46 respectively. While the detail assessment report on MDGs is yet to come, what we can 
speculate relative higher proportion of neonatal deaths, which has remained stagnant over the years has bulged IMRs and U5MR from decreasing. Tremendous efforts are necessary in immunization, growth monitoring, and control of diarrheal disease in urban slums, geographical remote and marginalized communities. Immunization for children is free of cost and provided from the health facilities and EPI clinics. However, it suffers from underreporting and over reporting problems in many districts. Factual immunization coverage is important for public health planning. Efforts are necessary to decrease and sustain the prevalence of major childhood killer diseases including under nutrition. Nepal has been declared polio free in 27th March 2014, sustained maternal and neonatal tetanus elimination since 2005, and Japanese encephalitis is in control status and is conducting measles case based surveillance to meet the target of elimination by 2019 .

\section{Stagnant Improvement on Maternal Health}

Though we do not have a separate MMR estimate for 2015, still data for 2011 suggest Nepal, would have missed MDG on maternal health by a margin. According to WHO 2011, MMR reached to 170 which is still less to the target set $134(3,4)$. According to Annual report 2070/71, the increasing trend in the institutional delivery in terms of expected pregnancy from $45 \%$ to $50 \%$ compared to previous year and similar percent increase in SBA delivery shows the effort towards safe motherhood. The screening of cervical cancer and its prevention was given full emphasis to identify new cases and treatment. Also, different level of services like comprehensive emergency obstetric and neonatal care, provision of emergency fund to ease the complication during pregnancy either through services or referral is in increasing trend. Aama surakshya karyakram and nyano jhola were continued to promote institutional delivery and prevent death of neonates due to hypothermia in 2015.

\section{Moving towards sanitation for all}

WHO estimates that improved water supply reduces diarrheal morbidity by $21 \%$ whileimproving sanitation by $37.5 \%$.Despite of gradual achievement in sanitation, only $62 \%$ of the country population were enjoying improved sanitation and was needed to increase access upto $98 \%$ to achieve MDGs. As sanitation coverage is measured in terms of toilet coverage so sanitation is often confused as open defecation free zone. Toilet construction is ongoing in coordination of Government, UNICEF, and other INGOs and local NGOs. This campaign aims to declare the nation in itself open defecation free zone by marking open defecation free status from village to village, village to city, city to city and finally whole nation. Around $88 \%$ of population had provision of safe drinking water till now. Around 65\% school facilities have provision of functional separate toilet for boys and girls and the water supply around $76 \%$ (5). Policies on solid waste management, national water supply sector policy, rural and urban water supply highlighted on the importance of hygiene and sanitation and its role to improve public health. Sanitation and Hygiene Master Plan, 2011 was enforced to maintain uniformity and standards in program approaches and to resolve initial gaps. This aims to unify stakeholders' through formation and mobilization of WASH Coordination Committee at different levels, fulfill resource gaps in the sectors and co-funding arrangements at local levels to ultimately achieve universal coverageon improved sanitation by 2017.

Intensifying Tobacco advocacy

Government has put forward the policy of making country tobacco free nation to reduce the consumption of tobacco products before and after ratification in Framework convention on tobacco control, 2003. Previously health warning either text or pictures needed to cover $75 \%$ of (both front and back) cigarette packets in print whereas in 2015 it was revised and made $90 \%$ of the packet(both front and back) should be covered with health warnings made of text or pictures in all tobacco products. This makes Nepal one countries with most stringent rules for tobacco packaging, surpassingIndia which requires $85 \%$ coverage. There is also a penalty of Rs. 10,000 for anyone who sell tobacco products to pregnant women and those less than eighteen years. Educating or raising awareness is one of the important strategies to reduce the use of tobacco adopted by Nepal. Therefore, enough efforts for awareness on harms of tobacco use are necessary, through institutional support and funding to tobacco advocacy.

\section{Moving towards sustainable development goals}

With the end of MDGs, the new sustainable development goals (SDGs) are expected further Nepal's vision towards healthy and prosperous nation. SDGs are universal set of goals, targets and indicators that UN member states will be expected to use to frame their agendas and political policies over the next 15 years established in 25th September, 2015. The SDGs follow and expand on the millennium development goals (MDGs). There are altogether seventeen goals focusing on reducing poverty, food, health, women empowerment, energy, etc. SDGs has embraced goals from reducing non communicable diseases burdens to neglected tropical diseases and also the vision for healthy and livable cities has also been included.

In conclusion, 2015 was truly a heroic year in decades to remember. During which, not only new constitution has come out amidst of challenges, but also has given new hope for future. Remaining challenges in implementation of new constitution needs help from all sectors including health. An issue in new constitution which has been the cause for long protests in Nepal's southern plains has to be addressed quickly taking aspirations of ethnic Madhesis and Tharus. The country's path towards sustainable recovery after the two massive earthquakes should come along with restructuring and re-strengthening in health system.

\section{References}

1. Nepal. Humanitarian crisis after the Nepal earthquakes 2015: World Health Organization, Nepal; May 2015.

2. Nepal Earthquake 2015, Post Disaster Need Assessment. Nepal: National Planning Commission, GoN; 2015.

3. Nepal Millennium Development Goals, Progress report. Nepal: National Planning Commission, GoN: United Nations Country Team Nepal; 2013.

4. WHO, UNICEF, UNFPA and The World Bank estimates. Trends in maternal mortality: 1990 to 2010.

5. Country report on Sanitation, Sanitation for all: all for sanitation. Nepal: SACOSAN V; 2013. 